\title{
Does drought alter hydrological functions in forest soils?
}

\author{
Katharina F. Gimbel ${ }^{1}$, Heike Puhlmann ${ }^{2}$, and Markus Weiler ${ }^{1}$ \\ ${ }^{1}$ Hydrology, Faculty of Environment and Natural Resources, University of Freiburg, Freiburg, Germany \\ ${ }^{2}$ Forest Research Institute Baden-Württemberg, Freiburg, Germany \\ Correspondence to: Katharina F. Gimbel (katharina.gimbel@hydrology.uni-freiburg.de)
}

Received: 22 June 2015 - Published in Hydrol. Earth Syst. Sci. Discuss.: 10 August 2015

Revised: 18 January 2016 - Accepted: 29 February 2016 - Published: 1 April 2016

Abstract. Climate change is expected to impact the water cycle and severely affect precipitation patterns across central Europe and in other parts of the world, leading to more frequent and severe droughts. Usually when projecting drought impacts on hydrological systems, it is assumed that system properties, like soil properties, remain stable and will not be affected by drought events. To study if this assumption is appropriate, we address the effects of drought on the infiltration behavior of forest soils using dye tracer experiments on six sites in three regions across Germany, which were forced into drought conditions. The sites cover clayey-, loamy- and sandy-textured soils. In each region, we compared a deciduous and a coniferous forest stand to address differences between the main tree species. The results of the dye tracer experiments show clear evidence for changes in infiltration behavior at the sites. The infiltration changed at the clayey plots from regular and homogeneous flow to fast preferential flow. Similar behavior was observed at the loamy plots, where large areas in the upper layers remained dry, displaying signs of strong water repellency. This was confirmed by water drop penetration time (WDPT) tests, which revealed, in all except one plot, moderate to severe water repellency. Water repellency was also accountable for the change of regular infiltration to fingered flow in the sandy soils. The results of this study suggest that the drought history or, more generally, the climatic conditions of a soil in the past are more important than the actual antecedent soil moisture status regarding hydrophobicity and infiltration behavior; furthermore, drought effects on infiltration need to be considered in hydrological models to obtain realistic predictions concerning water quality and quantity in runoff and groundwater recharge.

\section{Introduction}

Soils moderate how water moves through the vadose zone and govern the percolation of water to groundwater and streamflow. Soils not only store water for plant growth, function as a habitat for different biota and as transition zone to groundwater, but also are important - especially the top layers - for sorption and degradation of contaminants and (agri-)chemicals (Hendrickx and Flury, 2001). The efficiency of this important ecosystem service for groundwater and surface water protection depends on the behavior of pollutants in the soil and the hydrological transport processes (Keesstra et al., 2012). How fast water passes the vadose zone depends on its hydraulic soil properties and distribution such as pore volume distribution, soil aggregation, water repellency and rooting pattern.

Due to climate change and increasing human intervention, the global water cycle is expected to change with summer dryness and winter wetness in many regions across the world probably increasing, including western and central Europe (IPCC, 2012; Prudhomme et al., 2014). In addition, droughts are expected to be more frequent and severe in the future (Prudhomme et al., 2014; Seneviratne et al., 2006). Drought conditions can alter the hydrological functions of soils, and soil structure responds to drought with shrinkage and fracturing of soil aggregates. These soil shrinkage cracks channel the infiltrating water and therefore foster the bypassing of the soil matrix (Hendrickx and Flury, 2001; Ritsema et al., 1997) and alter the infiltration patterns in soil. Thus, the infiltration and redistribution of water within the soil changes and hence also the proportion of water reaching the groundwater (Hendrickx and Flury, 2001). 
Soils under drought conditions are prone to become water repellent, depending on soil properties and organic matter content (DeBano, 1981, 2000). Due to modifications of the three-dimensional distribution and dynamics of soil moisture, water repellency has far reaching consequences for infiltration processes (Doerr and Ritsema, 2006). Water repellency hinders infiltration and thus either increases overland flow (Doerr and Ritsema, 2006) or redirects the water into preferential flow paths and creates instable wetting fronts (fingered preferential flow; Ritsema et al., 1993; Ritsema and Dekker, 2000; Dekker and Ritsema, 2000).

To assess the impacts of drought, rainfall exclusion experiments are valuable and often applied tools (e.g., English et al., 2005; Phillips et al., 2009; Da Costa et al., 2010; Kopittke et al., 2014), in addition to elevated $\mathrm{CO}_{2}$ concentrations (e.g., Dermody et al., 2007), and nighttime warming (e.g., Albert et al., 2011; Selsted et al., 2012). While many studies focus on single aspects of drought effects like plant growth and seedling activity (Meijer et al., 2011; Wu and Chen, 2013) or on particular ecosystems like grassland (Suttle and Thomsen, 2007; Bütof et al., 2012) and heather ecosystems (Albert et al., 2011; Selsted et al., 2012), only few studies focus on forest ecosystems or take a closer look at drought impacts on soils where often only soil moisture is observed to change and no variations in other soil properties are monitored (Ozolinčius et al., 2009; Albert et al., 2011; Glaser et al., 2013).

To study drought effects, often extreme short-term events equivalent to droughts with occurrence probabilities of up to 100 or even 1000 years have been introduced to the examined soils (e.g., Glaser et al., 2013). By introducing these extreme events, the question of transferability of the results to natural systems in respect to the expected behavior under predicted future drought conditions arises. Therefore, this study employs a moderate rainfall reduction equivalent to an annual drought with a 40-year return period, in accordance to climate predictions, thereby avoiding tentativeness due to an overreaction to an unnatural extreme drought (Gimbel et al., 2015).

To monitor changes in soil hydraulic properties, the changes in infiltration patterns in the soil after 2 years of prolonged drought were observed in three regions across Germany. Infiltration patterns were chosen because they reflect the integrated changes of soil hydrological functions and directly show how water moves in the soil under altered conditions. In this paper, we present results of several dye tracer infiltration experiments before and after 2 years of prolonged artificial drought. The objectives of this study are (i) to investigate whether droughts predicted by climate projections affect the infiltration behavior of forest soils, and (ii) whether changes in infiltration patterns can be attributed to changes in the hydrologic properties of the soils. Three hypotheses will be tested: induced drought alters infiltration patterns due to changes in soil hydraulic properties, e.g., soil water repellency and the formation of shrinkage cracks, leading to

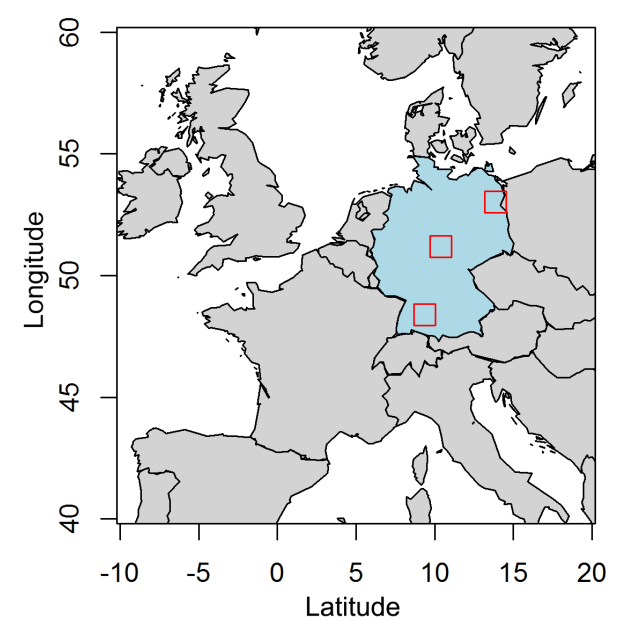

Figure 1. Location of the study sites (red squares) within Germany (light blue); southwest: Schwäbische Alb; center: Hainich-Dün; northeast: Schorfheide-Chorin.

preferential flow paths and faster infiltration; (2) the main tree species have an effect on the magnitude of the observed response and (3) the drought will increase water repellency depending on tree species and soil properties.

\section{Material and methods}

\subsection{Study sites}

To identify the influence of drought on infiltration patterns of forest soils, six plots in three different regions across Germany were selected. The plots were located in Schwäbische Alb (southwest Germany), Hainich-Dün (central Germany) and Schorfheide-Chorin (northeast Germany) (Fig. 1). All plots are part of the Biodiversity Exploratories framework that incorporates, in total, 150 sites on grassland and 150 sites in forest (for more information on the Biodiversity Exploratories, refer to Fischer et al., 2010). In each of the frameworks, two forest plots were selected, which are - within each framework - similar with respect to topography and soil texture type (Fig. 2) but differ in tree species composition. In each site, one plot with a coniferous and one with a deciduous main tree species was selected. At the Schwäbische Alb and Hainich-Dün sites, beech (Fagus sylvatica) and spruce (Picea abies) were chosen, in Schorfheide-Chorin beech and pine (Pinus sylvestris).

The Schwäbische Alb soils are shallow ( 25 to $35 \mathrm{~cm}$ ) Leptosols on Jurassic shell limestone with a high stone content (Fig. 2, top panels). The mean annual temperature at this site is $6.5^{\circ} \mathrm{C}$ and the mean annual precipitation amounts to $940 \mathrm{~mm}$. The underlying geology of the Hainich-Dün is Triassic limestone. The soils at this site are loamy Stagnosols with depths between 45 and $65 \mathrm{~cm}$. At the Hainich-Dün site the mean annual temperature is $7.2^{\circ} \mathrm{C}$ and the mean annual 
Deciduous
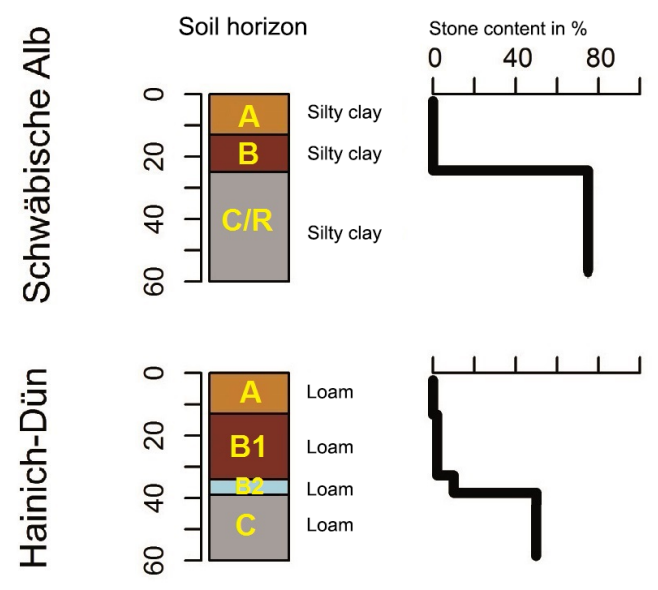

듬
$\frac{0}{0}$
$\frac{1}{0}$
$\frac{0}{0}$
$\frac{1}{4}$
$\frac{0}{0}$
엄
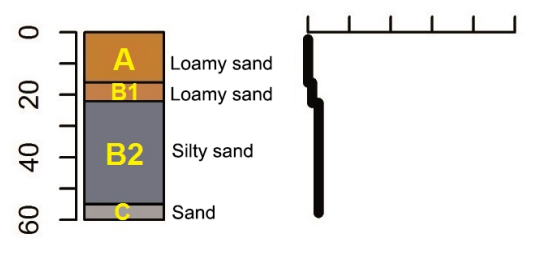
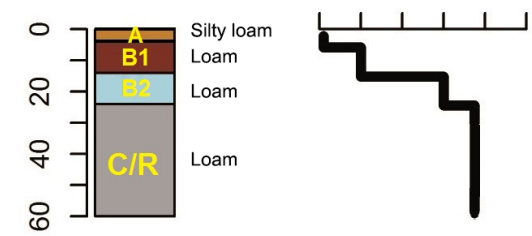

\section{Coniferous}
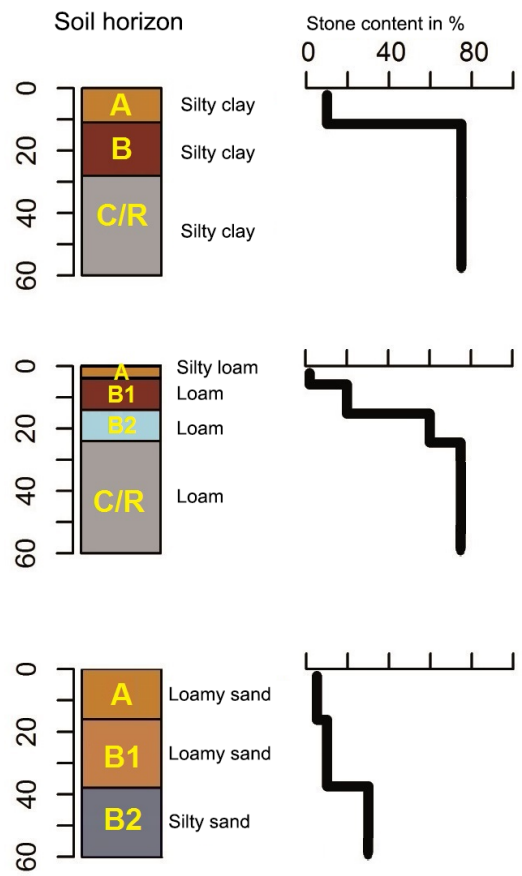

Figure 2. Soil horizons, texture and rock fractions of the six experimental plots. Soil type classification according to the World Reference Base for soil (FAO, 2006).

precipitation is $533 \mathrm{~mm}$. The Schorfheide-Chorin plots are located in a young glacial landscape where the dominant geological substrate is glacial till covered by glacio-fluvial and aeolian sands. The soils at this site are deep, sandy Cambisols. At the Schorfheide-Chorin site, mean annual temperature is $8.5^{\circ} \mathrm{C}$ and the mean annual precipitation amounts to $589 \mathrm{~mm}$. All climate data are taken from nearby stations of the German weather service (DWD; years 1950-2010).

The experiments of this study are part of the interdisciplinary project "Global Change Effects on Forest Understorey: interactions between Drought and Land-use Intensity" (Gimbel et al. 2015). The artificially imposed drought was created by a $10 \mathrm{~m} \times 10 \mathrm{~m}$ roofed subplot, covered with transparent panels. In addition, a control plot with the same technical equipment, but without the roofing was installed. The distance between the roofed and the control plots range between 15 and $30 \mathrm{~m}$. The control and roofed plots include a central adult overstorey tree, all of which are similar in age, size and canopy structure. To provide sufficient exchange with ambient air (avoiding a greenhouse effect), all four sides of the roof are open. To collect water from the roof, rain gutters are mounted alongside the timber construction. The roof is designed to reduce precipitation between 11 and 100-11\% already intercepted by the roofing construction and rain gutters itself. The incoming precipitation was reduced between March and November to the level equivalent to an annual drought with a return period of 40 years. The resulting annual target precipitation inputs under the roofs were $700 \mathrm{~mm}$ ( $26 \%$ reduction) for Schwäbische Alb, $355 \mathrm{~mm}$ (33\% reduction) at the Hainich-Dün and $395 \mathrm{~mm}$ (27\% reduction) at the Schorfheide-Chorin site. For a more detailed description of the whole experimental drought setting and of the study plots see Gimbel et al. (2015).

\subsection{Soil moisture measurements}

To observe the impact of reduced precipitation input on soil moisture, soil moisture probes were installed on the drought and on the control subplots of every site. The probes (5TM and 5TE, Decagon Devices Inc.) were inserted at 5, 15 and $30 \mathrm{~cm}$ depths in three replicates on the plots at 2,3 , and $4 \mathrm{~m}$ distance from the central trees. The accuracy according to the technical data sheets of the 5TE and 5TM probes is $\pm 15 \%$ of the measured value for the volumetric water content. The readings of every probe are logged at $15 \mathrm{~min}$ intervals. For better comparability among the sites, the mean values of the three replicates of every depth per control and drought plot were cumulated and normalized to the maximum cumulated value of the control plot. 

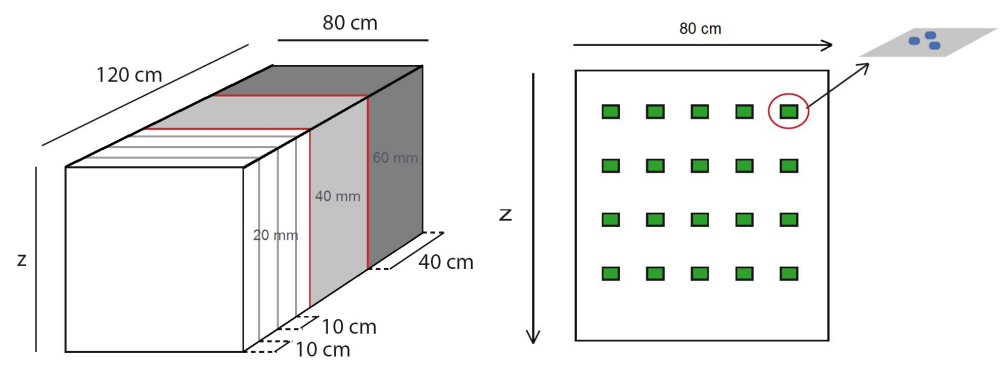

Figure 3. Scheme for profile excavation (a) and WDPT experiment (b). The 20, 40 and $60 \mathrm{~mm}$ in (a) denote the applied sprinkling volumes. For the WDPT experiment (b), five sampling locations (boxes) were used traversing the profile. On every sampling location, the tests were repeated 3 times.

\subsection{Soil water repellency}

Hydrophobicity in soil was measured with the water drop penetration time (WDPT) test (e.g., Bisdom et al., 1993). This test determines how long water repellency persists on a porous surface. The tests were performed immediately before the dye tracer experiments in 2013, in the drought and control profiles of the deciduous plots and in the drought profiles of the coniferous plots. For the WDPT tests, a water droplet is placed on a planar soil surface with a pipette and the time is measured until the water drop is completely taken up by the soil. The observation was stopped after exceeding a time of $3600 \mathrm{~s}$. Depending on the profile depths, WDPT tests were performed in several depths of the profile, covering the main soil horizontation. In each depth, five sampling locations were used to traverse the profile, and the tests were repeated 3 times per location, resulting in 15 WDPTs per depth (Fig. 3b). The mean and maximum values of the WDPT test were classified after Bisdom et al. (1993) (Table 1).

\subsection{Dye tracer experiments}

The dye tracer experiments were conducted in August 2011 before installation of the roofs and in August 2013 after 2 years of drought. For each experiment, an area of $80 \mathrm{~cm} \times 120 \mathrm{~cm}$ was prepared by cutting smaller vegetation (grasses, herbaceous plants, and small tree offshoots), covering the surroundings with a thin plastic sheet, and dividing the area into three sub-areas with a size of $80 \mathrm{~cm} \times 40 \mathrm{~cm}$ each (Fig. 3a). The experimental area was kept shaded and sheltered from rain in all weather conditions to minimize evaporation and uncontrolled water input during the experiments. Brilliant Blue FCF was diluted in water of local origin to a concentration of $4 \mathrm{~g} \mathrm{~L}^{-1}$ and was sprayed with a backpack nozzle sprayer for even distribution (Bachmair et al., 2009). For an overall application amount of 20, 40 and $60 \mathrm{~mm}$, each sub-area was sprinkled with an intensity of $20 \mathrm{~mm} \mathrm{~h}^{-1}$. The applied rainfall intensity of $20 \mathrm{~mm} \mathrm{~h}^{-1}$ reflects a heavy rainfall event in all regions; therefore, the sprinkling amounts simulate 1,2 and $3 \mathrm{~h}$ of heavy rainfall. After sprinkling, the experimental area was covered with
Table 1. Classification of water repellency by WDPT, after Bisdom et al. (1993).

\begin{tabular}{llc}
\hline WDPT (s) & Classification & Class \\
\hline$<5$ & wettable & 1 \\
$5-60$ & slightly water repellent & 2 \\
$60-600$ & strongly water repellent & 3 \\
$600-3600$ & severely water repellent & 4 \\
$>3600$ & extremely water repellent & 5 \\
\hline
\end{tabular}

plastic sheets to prevent evaporation and further water input through eventual rain.

The next day (after waiting at least $12 \mathrm{~h}$ ), three vertical soil profiles per sub-area were prepared. Keeping a $10 \mathrm{~cm}$ buffer stripe at the beginning and between the individual sub-areas, every sub-area was divided in three sections, spaced $10 \mathrm{~cm}$ from each other (Fig. 3a). To obtain the dye pattern, the surface of the excavated soil profiles was smoothed with a spatula and loose particles were removed with a brush, avoiding smearing. Stones were left in place and shaped into relief when needed. Roots were trimmed. Pictures were taken from each profile with a standard digital compact camera with a resolution of 10 megapixels $(3648 \times 2736$ pixel). The single profiles were photographed with a ruler frame and a grey scale under even illumination and different illumination settings (Weiler and Flühler, 2004). The picture with the best image quality from each profile was used for further processing.

\subsection{Image processing and data analysis}

To objectively compare the flow pattern of the different profiles, we used the image analysis procedure developed by Weiler and Flühler (2004). We provide a short description of the process here, for more detailed information, refer to Weiler (2001) and Weiler and Flühler (2004). The image processing consists of three main steps. In the first step, geometric distortion of the image is corrected by establishing a relationship between the image pixel location and the true location on the soil profile. During this step, the image is 
also scaled such that, one pixel corresponds to a square of $1 \mathrm{~mm} \times 1 \mathrm{~mm}$. In the second step, the spectral composition changes in daylight are balanced to ensure inter-picture comparability. This is done by a color adjustment of the image using the photographed grey scale. In the third step, the images are classified into stained and unstained areas. Applying a semi-supervised classification technique, a binary image of stained versus unstained areas is obtained. In contrast to the work of Weiler and Flühler (2004), we did not use the information of different dye tracer concentrations, due to the high heterogeneity of the background color. In this step, objects like stones and vegetation are manually digitized, too. All calculations were done with the programming language IDL (Interactive Data Language; Exelis Inc.).

\subsection{Dye pattern analysis}

To obtain objective measures to compare the dye patterns of the different profiles and sites, we derived three depthrelated variables of the binary images: (1) volume density, (2) surface density and (3) stained path width as basis for further delineation of flow processes. The volume density (VD) is similar to the frequently used dye coverage. It is defined as the stained volume divided by the reference space and originated from the methods of stereology, which relates a three-dimensional parameter to two-dimensional measurements (Weibel, 1979). Surface density (SD) is defined as surface area of an object divided by the volume of the reference space. Surface density provides information on the size and number of features: a high SD is caused by a large number of small objects, whereas a low SD indicates less but larger objects (Weiler, 2001). The stained path width (SPW) is derived by measuring the width of every stained object at a certain depth. The SPWs of every depth were classified into three classes of $<20,20-200$, and $>200 \mathrm{~mm}$ (Weiler and Flühler, 2004). The sum of the three SPW classes per depth corresponds to the VD of the regarding depth. Using the frequency distribution of the SPW of every depth, the dye pattern can be related to distinct flow processes. For example, macropore flow with low interaction can be identified by long and narrow stains, whereas macropore flow with mixed interaction shows a broader distribution of shapes (Weiler and Flühler, 2004). The classification introduced by Weiler and Flühler (2004) was used to distinguish five flow processes, depending on the proportion of stains in each SPW class: two types of matrix flow - (1) homogeneous and (2) heterogeneous - and three types of macropore flow - (3) low, (4) mixed and (5) high interaction with matrix - where interaction is understood as the lateral water flow from macropores into the surrounding soil matrix (Weiler and Naef, 2003). To assess the differences in the VD values between the treatments (pre-drought, control, drought), the Kruskal-Wallis test and the Nemenyi post hoc test were applied, using R (version 3.2.3, The R Foundation for Statistical Computing, 2015) and the package PMCMR (version 4.1 by Thorsten Pohlert) within. Differences between treatments were assumed to be significant, when $p$ values are $\leq 0.01$.

\section{Results}

\subsection{Soil moisture}

Figure 4 shows the normalized cumulated sums of the soil moisture measurements of the control and the drought plots over the course of 2 years. All plots developed a soil moisture deficit compared to the control plots in the upper $5 \mathrm{~cm}$ of the soil, as shown by the black line below the $1: 1$ line. The water deficit is also transduced to 15 and $30 \mathrm{~cm}$ depths in both Schwäbische Alb plots and in the coniferous plot of Hainich-Dün, but is generally less pronounced. The plots at the Schorfheide-Chorin site show no deficit (deciduous plot) or even a small plus in soil moisture (coniferous plot) compared to the control plot. The sandy soils of SchorfheideChorin are already very dry without drought treatment. The reverse moisture effect might be caused by effects associated with the installation and placement of the probes (e.g., preferential flow along probe cables, concentration of throughfall - although installations were performed with great care), or root effects, e.g., hydraulic redistribution. However, we did not find any signs for hydraulic redistribution in the data. The deciduous plot of the Hainich-Dün site experienced major probe failures due to animal damage during the summer months of 2012 and again in 2013. Therefore, only the data taken during the winter months could be used for the comparison. For this reason, the data do not cover the months with the highest expected soil moisture deficits.

\subsection{Soil water repellency}

Figure 5 shows the results of the WDPT test in 2013. All drought-treated plots at all sites - coniferous and deciduous - exhibit water repellency (WDPT data from control plot under coniferous not available). All control plot soils are wettable (WDPT class 1) or feature at least lower water repellency than the drought-treated plots. The coniferous plots under drought of Hainich-Dün and Schwäbische Alb showed higher WDPTs than the deciduous plots. This is valid for both mean and maximum values. The SchorfheideChorin deciduous plot showed higher water repellency than the coniferous plot. In all soil profiles, water repellency is the highest in the topsoil and diminishes at a depth of about $20 \mathrm{~cm}$. However, in the Schorfheide-Chorin deciduous plot, water repellency is present up to a depth of $50-60 \mathrm{~cm}$. When present, strong to severe water repellency is dominant in the measured drought-treated plots. Only the Hainich-Dün deciduous plot soil is classified as wettable on average and the Schorfheide-Chorin coniferous plot as slightly water repellent. The highest values in mean and maximum water repellency were found in the coniferous plots Hainich-Dün (mean $941 \mathrm{~s}$; max $3600 \mathrm{~s}$ ) in about $10-15 \mathrm{~cm}$ depth and in 

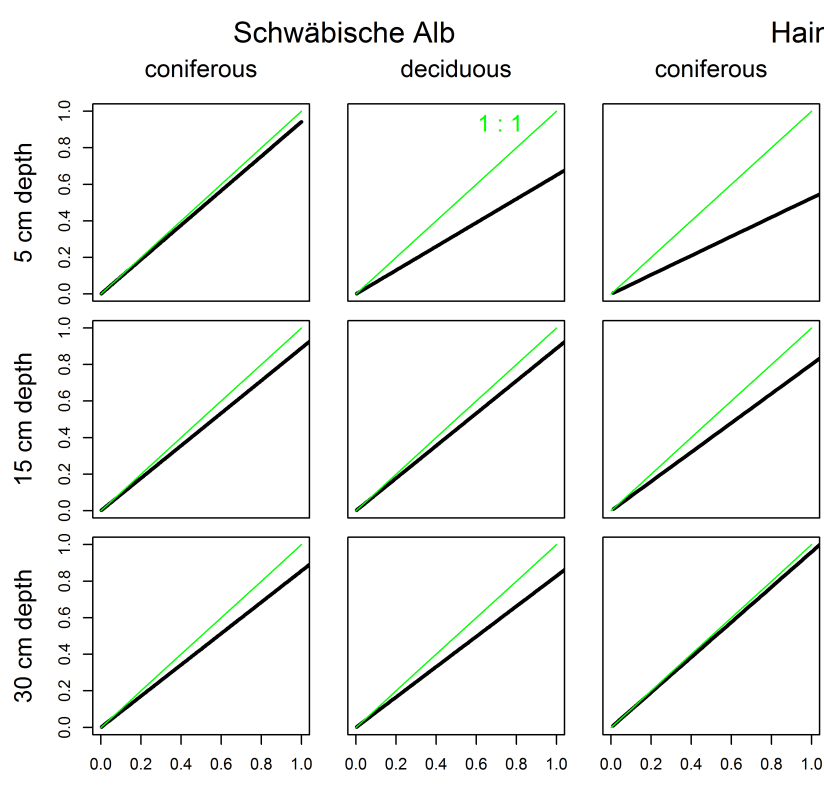

ainich-Dün

deciduous
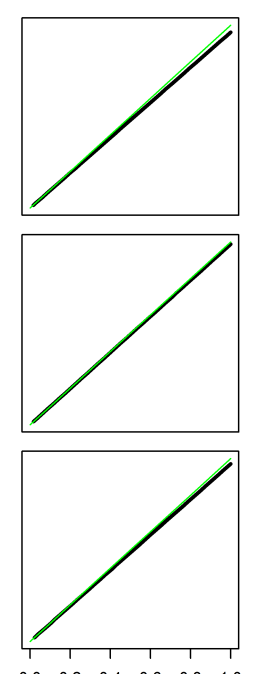

$\begin{array}{llllll}0.0 & 0.2 & 0.4 & 0.6 & 0.8 & 1.0\end{array}$

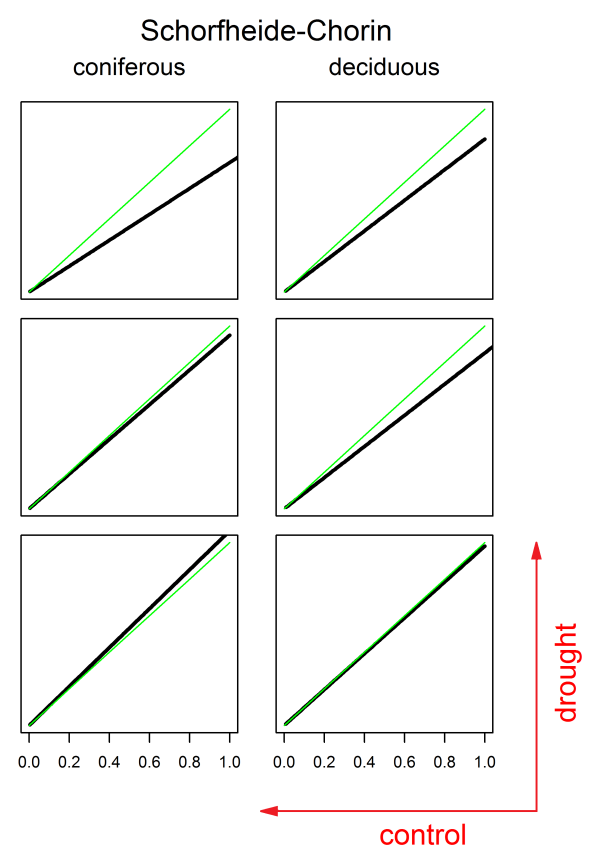

Figure 4. Normalized cumulated sums of soil moisture of the drought versus the control subplots of the investigated soils. The computations begin with the start of the rainfall reduction and end at the date of the dye tracer experiment 2013.

the Schwäbische Alb (mean 990 s; max 2340 s) in the topsoil (Fig. 5).

\subsection{Dye tracer experiments and dye pattern analysis}

\subsubsection{Comparison between pre-drought pattern and control pattern}

Differences between pre-drought and control plots (without drought treatment) not only reflect differences in soil structure, texture and moisture due to a distance of $20-40 \mathrm{~m}$ between the drought and reference plot, but also may include time-dependent changes of the soil characteristics, which are independent from the drought treatment. To ensure validity of the dye pattern analyses, it is necessary to assure comparability among the plots. To exclude time-dependent changes as reasons for differences in pre-drought and drought-treated dye patterns, the pre-drought patterns were checked against the patterns of the control plots. Figure 6 compares the predrought pattern and the control pattern of the deciduous plots. In addition, Fig. 7 provides box plots of VD for different depths of the pre-drought and the control profiles for direct comparison.

The Schwäbische Alb pre-drought plot (Fig. 6, top left panel) shows high VD in the top $10 \mathrm{~cm}$ in all profiles. The 40 and $60 \mathrm{~mm}$ sprinkling volume profiles show a high SPW in the top 5 to $10 \mathrm{~cm}$. On the control plot (Fig. 6, top right panel) large areas of the profiles top $10 \mathrm{~cm}$ are also stained, but the VD and SPW are not as high as the pre-drought profiles. This is especially evident in the VD box plots of the upper 0-10 cm (Fig. 7, top panels). All Schwäbische Alb profiles have high stone contents, in some cases exceeding $50 \%$ of the profile width (Fig. 6). Below $10 \mathrm{~cm}$ depth, the control plot profiles are almost completely stained. This pattern is similar to the pre-drought profiles. In general, the patterns of the control profiles are similar in VD, SPW values and distribution to the $20 \mathrm{~mm}$ pre-drought profile. The $60 \mathrm{~mm}$ control profile reflects the high VD and SPW values in top layers, which are characteristic of the 40 and $60 \mathrm{~mm}$ pre-drought profiles.

The Hainich-Dün pre-drought profiles (Fig. 6, center left panel) show low to medium SPW in all depths. VD values are high in the top $5 \mathrm{~cm}$ in all profiles and between 10 to $30 \mathrm{~cm}$ in the 40 and $60 \mathrm{~mm}$ sprinkling amount profiles. The $20 \mathrm{~mm}$ profile displays only small VD values below $10 \mathrm{~cm}$ depth. All profiles have a medium to high stone content (30-60\%) below $30 \mathrm{~cm}$ depth. The control plot profiles (Fig. 6, center right panel) are very similar in VD and SPW to the predrought profile pattern, but with generally lower VD in the $60 \mathrm{~mm}$ sprinkling amount profile (Fig. 7, center right panel). Except for the $20 \mathrm{~mm}$ profile, which displays no stones, the control plot profiles have a medium to high stone content below $25 \mathrm{~cm}$ depth. In all profiles, large areas of the profile stayed unstained. However, although having a low VD in top layer, the $60 \mathrm{~mm}$ control plot profile is not following the pronounced drop in VD between 5 and $10 \mathrm{~cm}$ depths and the subsequent rise between 15 and $25 \mathrm{~cm}$, which is characteristic for all other profiles (pre-drought and control). These distinct differences are apparent in the box plots (Fig. 7). 


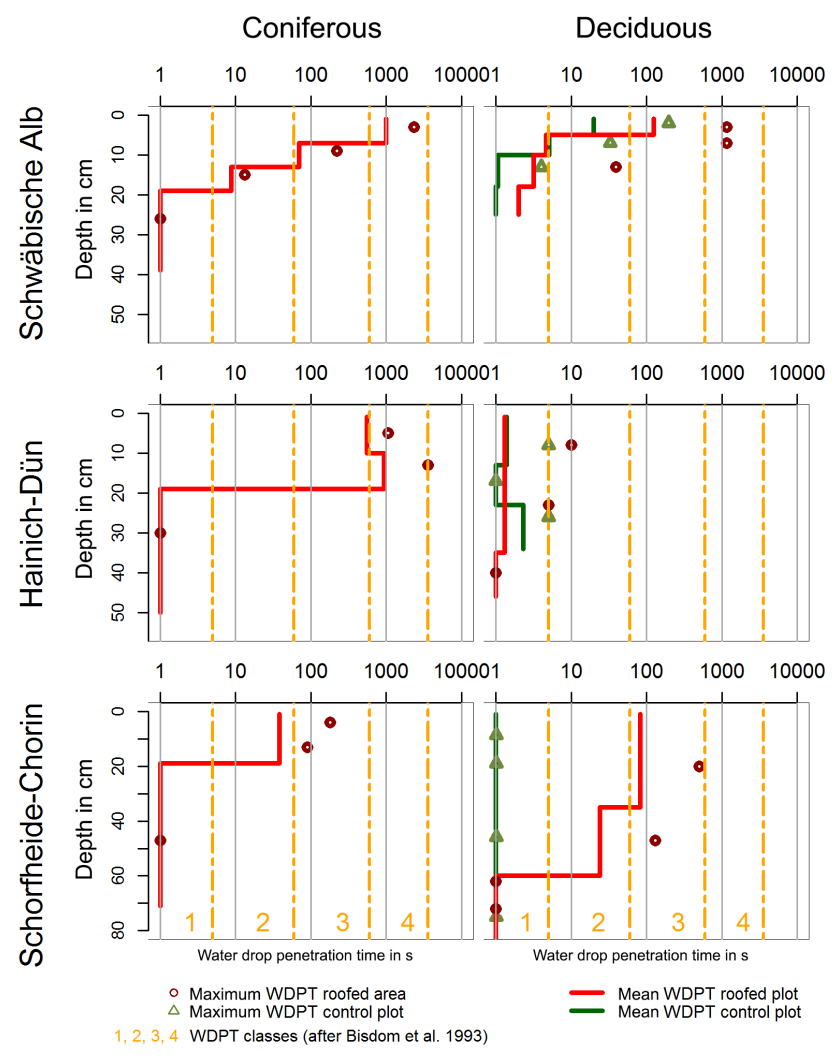

Figure 5. Mean and maximum water drop penetration times (WDPTs) of the control (green) and drought (red) plots. Orange lines and numbers refer to the WDPT classes after Bisdom et al. (1993) (see Table 1).

In the Schorfheide-Chorin pre-drought profiles (Fig. 6, bottom left panel), high VD and SPW values are present. The highest VD and SPW values can be found in the $60 \mathrm{~mm}$ sprinkling amount profile. Below $10 \mathrm{~cm}$ depth, the $20 \mathrm{~mm}$ predrought profile displays only small to medium SPWs and - in comparison to the 40 and $60 \mathrm{~mm}$ profiles - small VD values. The control plot profiles (Fig. 6, bottom right panel) show, in general, high VD and SPW values, but have lower values in the top $10 \mathrm{~cm}$ than the pre-drought profiles (Fig. 6, bottom right panel and Fig. 7, bottom panels). This is more apparent in the 20 and $40 \mathrm{~mm}$ profiles (Fig. 7). In the pre-drought and control plots, infiltration reached down to depths of over $70 \mathrm{~cm}$ and no stones are present.

To summarize, the comparison between the pre-drought and control plots showed a broad agreement. Differences, that need to be accounted for, are the lower VD in the profile top layers, especially at the Schwäbische Alb and Schorfheide-Chorin site. These differences might be due to spatial heterogeneities, e.g., slight differences in soil layer boundary depths, given the distance between the control and the pre-drought plots ( 15 to $30 \mathrm{~m}$ ). In addition, the initial conditions (soil moisture) were also slightly different possibly resulting in the observed differences. Choosing $10 \mathrm{~cm}$ steps for statistical comparison of the VD may in addition introduce differences, if soil layer boundary depths differ. Therefore, not only the VD, but also the SPWs and the determined flow processes need to be taken into account for comparison. However, the pre-drought and drought experiment were performed in close vicinity $(1 \mathrm{~m})$. In the Hainich-Dün, the drop and rise of VD in all profiles points to a soil layer boundary effect on infiltration. This is not time dependent and present in both pre-drought and control profiles; therefore, the comparability between the pre-drought and drought pattern is not affected.

\subsubsection{Comparison between pre-drought pattern and drought pattern}

As can be seen in Fig. 8, all plots show marked differences between pre- and after-drought infiltration patterns. The clayey and loamy sites (Schwäbische Alb and HainichDün) develop unstained (i.e., unwetted) areas in the topsoil layers. This is more pronounced in the coniferous plots, where unstained areas are already visible in the pre-drought infiltration pattern. Figure 9 compares VDs in box plots for different depths of the drought and pre-drought profiles including the statistical significance.

\section{Schwäbische Alb coniferous plot}

At the Schwäbische Alb site, medium to low volume densities (VDs) were found on the pre-drought coniferous plot throughout the whole profile for the 20 and $40 \mathrm{~mm}$ sprinkling depth and high VD for $60 \mathrm{~mm}$ sprinkling depth (Fig. 8, top left panel). The drought 40 and $60 \mathrm{~mm}$ profiles are lower in VD in the top layers $(0-10 \mathrm{~cm})$, than the pre-drought profiles (Figs. 8 and 9, top left panels); the $40 \mathrm{~mm}$ profile displays even unstained areas (no VD). The $20 \mathrm{~mm}$ pre-drought profile is already very low in VD; therefore, the differences to the after drought profile are not distinct (Fig. 8, top left panel). The drought coniferous plot shows a rise of VD culminating around $20 \mathrm{~cm}$ depth (Fig. 8, top panels) for all sprinkling amounts (20, 40 and $60 \mathrm{~mm})$. Below $20 \mathrm{~cm}$ depth, the 20 and $40 \mathrm{~mm}$ profiles show (Fig. 9, top left panel) higher VD in the after drought profiles than in the pre-drought profiles, whereas the $60 \mathrm{~mm}$ profile show the same extent of VD in the drought and in the pre-drought profile.

The stained path widths (SPWs) of the Schwäbische Alb coniferous pre-drought profiles are small to medium in the 20 and $40 \mathrm{~mm}$ profiles and high in the $60 \mathrm{~mm}$ profile (Fig. 8, top left panel). After drought, low to medium SPWs are dominant in the 20 and $60 \mathrm{~mm}$ profiles; high SPW values occur in the $40 \mathrm{~mm}$ profile below $20 \mathrm{~cm}$. The flow processes identified in this depth as matrix flow, are caused by local saturation due to low $K_{\mathrm{s}}$ (Fig. 8, top left panel). The dominating flow types in the pre-drought profiles are identified as macropore flow, with low, mixed and high interaction depending on soil layer and infiltration volume. Dominating flow types in the 


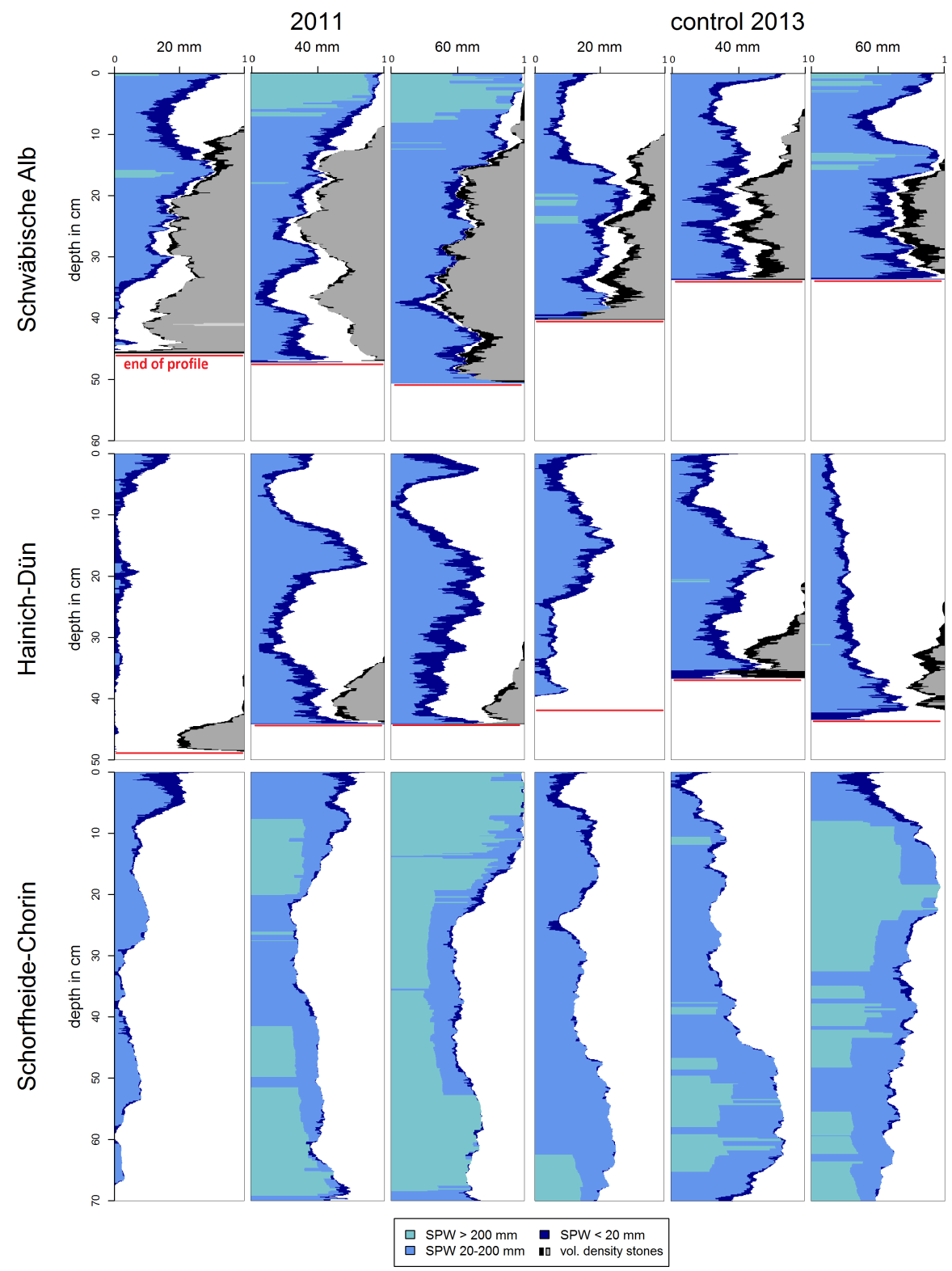

Figure 6. Comparison between stained path width (SPW) of pre-drought (2011) and control (2013) plot. Blue shades indicate the SPW classes. The sum of SPW is the volume density (VD) per depth. Grey and black indicate the VD of stones.

drought plot are macropore flow with low, medium and high interaction.

\section{Schwäbische Alb deciduous plot}

The Schwäbische Alb deciduous plot shows in the 40 and $60 \mathrm{~mm}$ pre-drought profiles high SPWs and in all infiltrating volumes high VDs in the top layer $(0-10 \mathrm{~cm}$; Figs. 8 and 9, top right panels). Medium to high VDs are maintained throughout the whole 40 and $60 \mathrm{~mm}$ profiles, and to lesser extend in the $20 \mathrm{~mm}$ profile. The drought profiles show lower VD in the top $10 \mathrm{~cm}$, compared to the pre-drought profiles
(Fig. 9, top right panel). Below 20-25 cm depths, the 20 and $40 \mathrm{~cm}$ drought profiles show higher VD than the pre-drought profiles. However, the drought profiles are more similar in shape to the VD pattern of the control than to the pre-drought profiles (Fig. 6, top panels). Also, the stone contents in the three pre-drought profiles are higher than in the drought profiles (Fig. 8, top right panel).

The dominating flow types in the Schwäbische Alb deciduous pre-drought profiles are identified as macropore flow with low, mixed and high interaction, and as matrix flow, depending on soil layer and infiltration volume (Fig. 8, top right panel). The flow processes identified in the top layers of the 

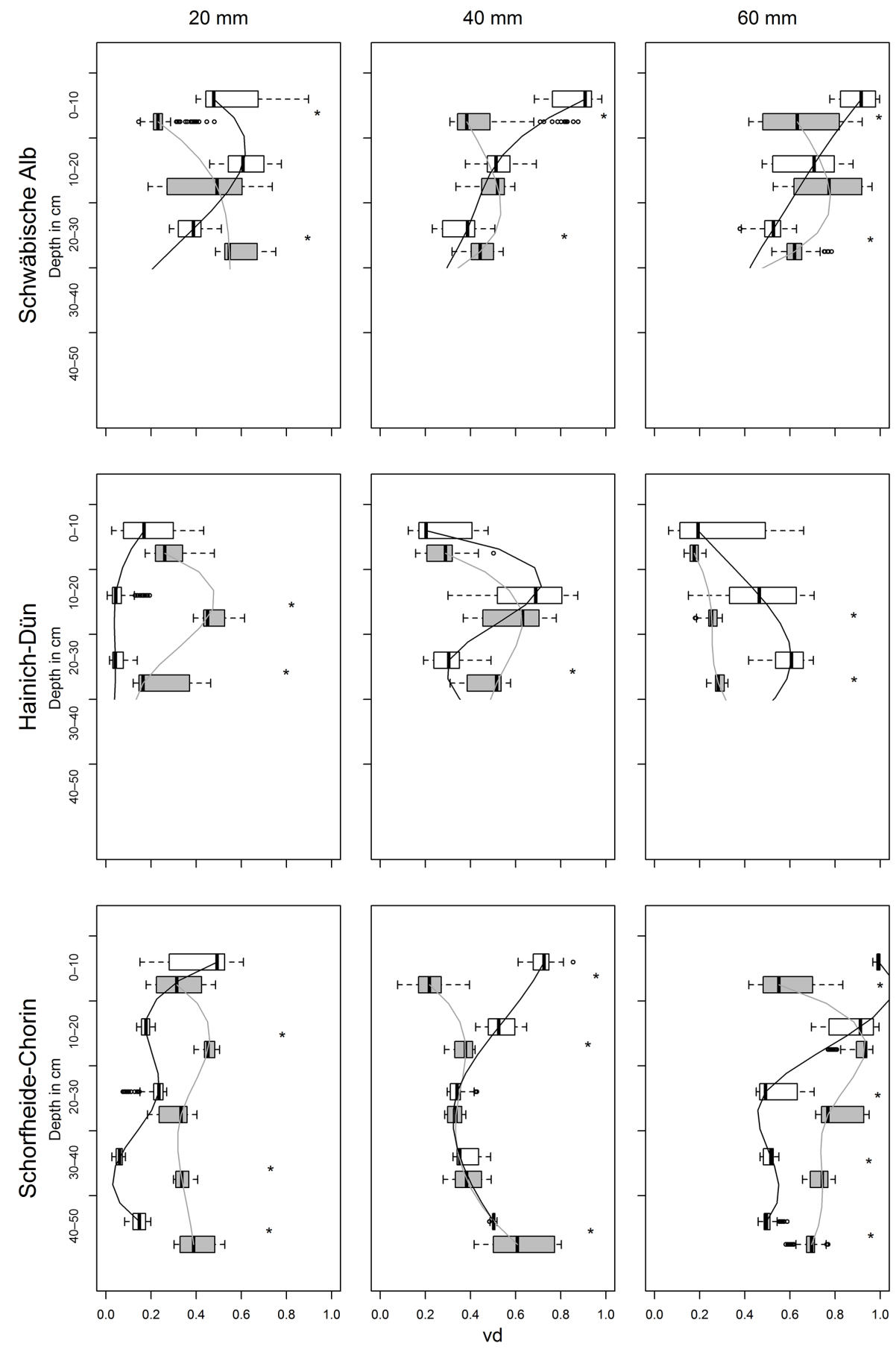

Pre-drought $\square$ Control

Figure 7. VD box plots of the drought and the pre-drought pattern. Depth ranges are omitted, where one of the profile is shorter than the other. Statistically significant $(p$ value $\leq 0.01)$ differences between the treatments are marked with an asterisk.

40 and $60 \mathrm{~mm}$ pre-drought profiles as matrix flow are caused by local saturation due to low $K_{\mathrm{s}}$. The dominating flow types of the drought deciduous profiles are identified as macropore flow with low, mixed and high interaction (Fig. 8, top right panel).

\section{Hainich-Dün coniferous plot}

The Hainich-Dün coniferous pre-drought profiles show low VD for all sprinkling amounts, especially in the topsoil between 4 and $22 \mathrm{~cm}$ (Fig. 8, center left panel). The 20 and 


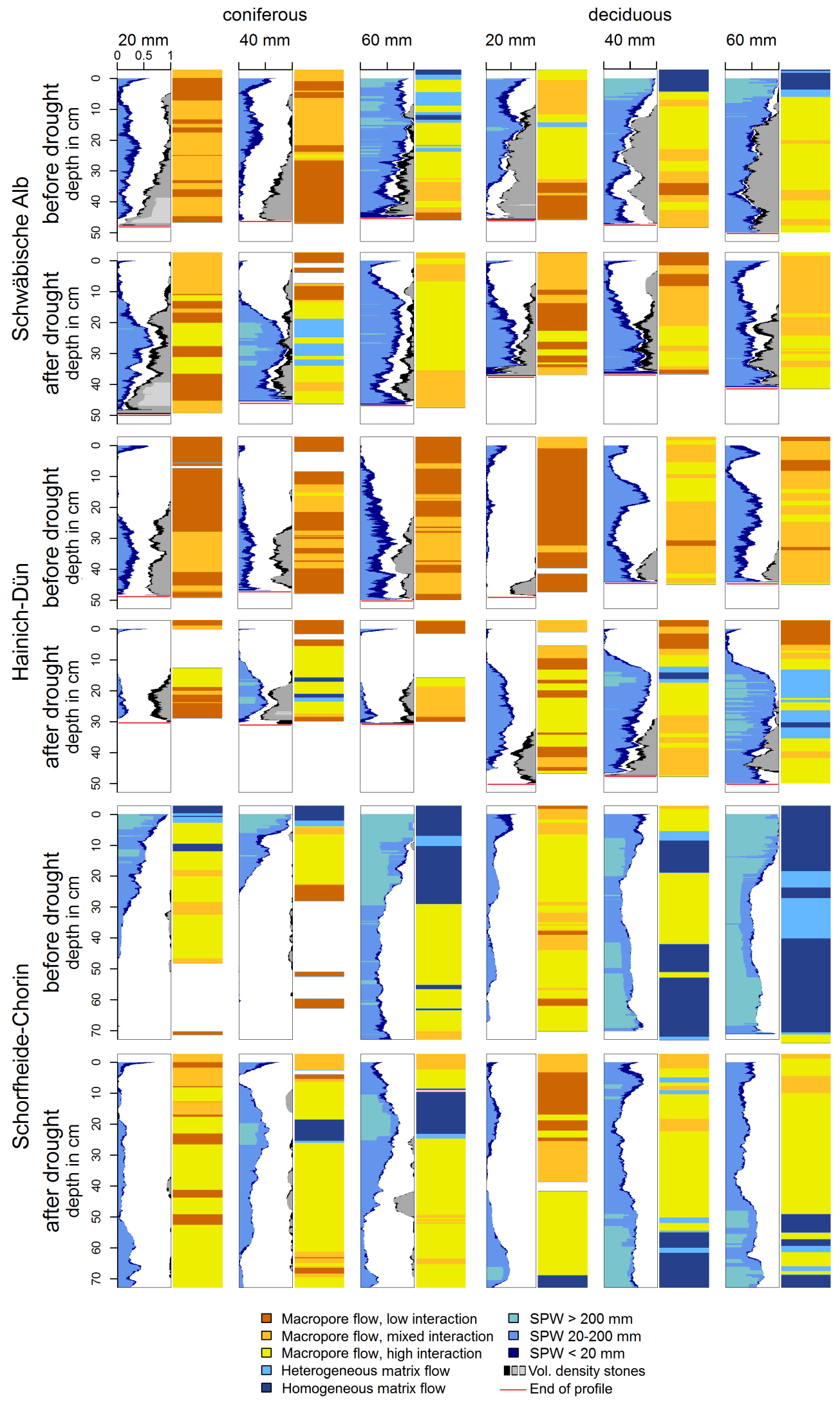

Figure 8. Comparison between before drought (2011) and after drought (2013) stained path widths (SPWs) and flow processes for coniferous and deciduous stand plots. The sum of SPW is the volume density (VD) per depth. Grey and black indicate the VD of stones. 

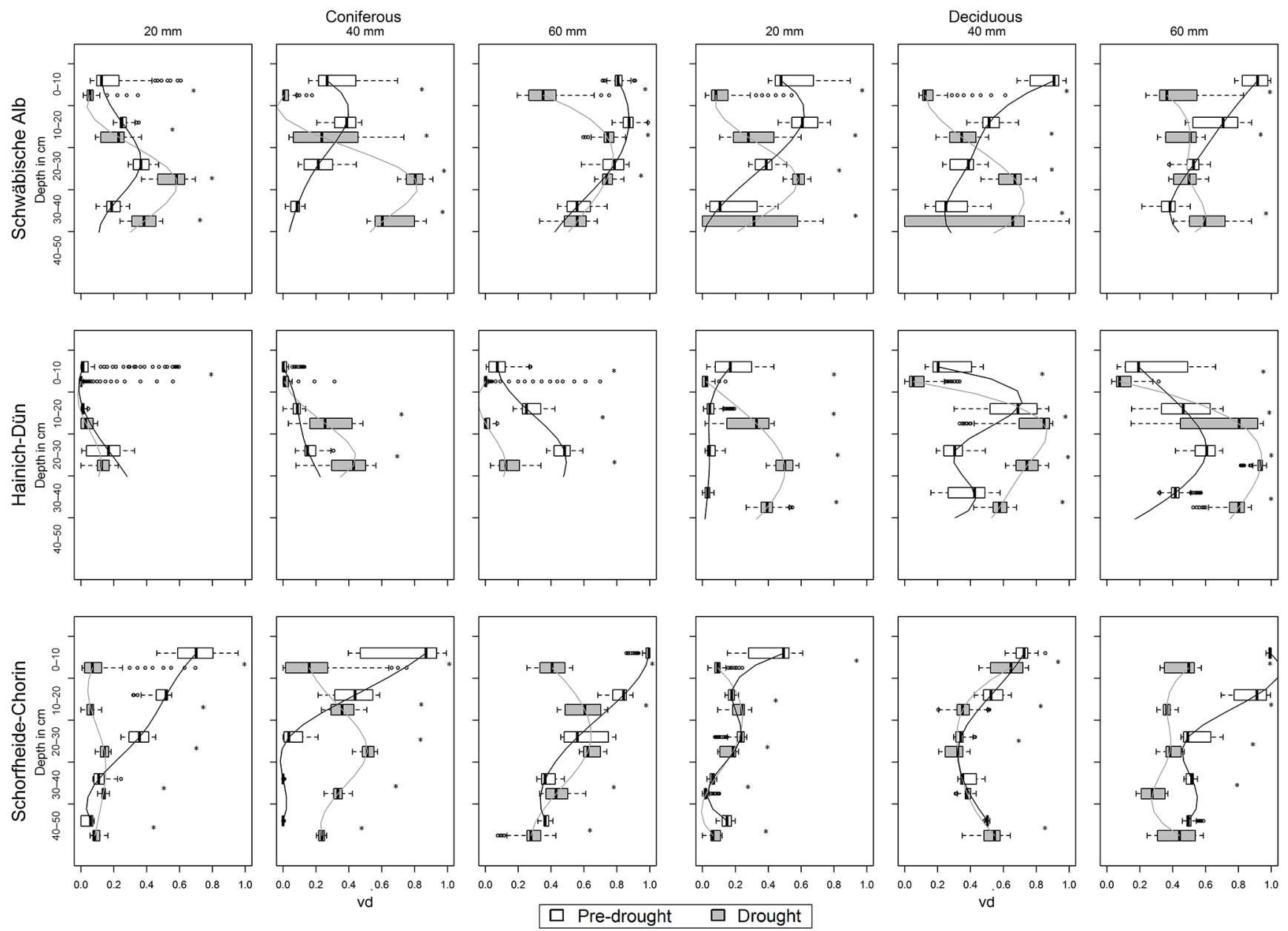

Figure 9. VD box plots of the drought and the pre-drought pattern. Depth ranges are omitted, where one of the profile is shorter than the other. Statistically significant ( $p$ value $\leq 0.01$ ) differences between the treatments are marked with an asterisk.

$40 \mathrm{~mm}$ pre-drought profiles show unstained areas (no VD). The small VD values are even more pronounced in the drought profiles (Figs. 8 and 9, center left panels), in which all profiles exhibit unstained areas. Below the unstained layer, the VD rises to a maximum in 15 to $20 \mathrm{~cm}$ depth and drops again around $30 \mathrm{~cm}$ depth. The 20 and $60 \mathrm{~mm}$ drought profiles show throughout all depths low VD (Fig. 8, center left panel).

In all Hainich-Dün coniferous pre-drought profiles, no large SPWs occur and flow types are classified as macropore flow with low, mixed and high interaction. This applies also for the 20 and $60 \mathrm{~mm}$ drought profiles. In contrast, the $40 \mathrm{~mm}$ drought profile exhibits high SPWs between 15 and $25 \mathrm{~cm}$ depth. Therefore, the flow types in these depths are identified as matrix flow (Fig. 8, center left panel). The main flow types in the coniferous drought profiles are macropore flow with low, mixed and high interaction. The pre-drought profiles are dominated by macropore flow with low and mixed interaction. In both, pre-drought and drought profiles, the stone content is comparable (Fig. 8, center left panel).

\section{Hainich-Dün deciduous plot}

The Hainich-Dün deciduous drought profiles exhibit smaller VD in the top $5 \mathrm{~cm}$ compared to the pre-drought profiles (Figs. 8 and 9, center right panels). Unstained areas are present in the top $5-10 \mathrm{~cm}$ of the $20 \mathrm{~mm}$ drought profile. The 40 and $60 \mathrm{~mm}$ pre-drought profiles show high VD values between 10 and $25 \mathrm{~cm}$. High VD values are also present in the drought profiles, maintaining high values throughout the whole profile. While no high SPW values are found in the pre-drought profiles, high SPW values can be found in the $40 \mathrm{~mm}$ drought profile between 10 and $30 \mathrm{~cm}$ and in the $60 \mathrm{~mm}$ drought profile between 10 and $40 \mathrm{~cm}$ (Figs. 8 and 9, center right panels). The flow types of the deciduous predrought profiles are classified as macropore flow with low, mixed and high interaction. The drought profiles are also classified as macropore flow with low, mixed and high interaction and, where high SPW values occur, as matrix flow (homogeneous and heterogeneous) (Fig. 8, center right panel). The stone contents of the pre-drought and drought profiles 
increase with depth below $25-30 \mathrm{~cm}$; the drought profiles exhibit a slightly higher stone content than the pre-drought profiles (Fig. 8).

\section{Schorfheide-Chorin coniferous plot}

The pre-drought pattern of the Schorfheide-Chorin site shows high SPWs and VDs in the top layers $(0-10 \mathrm{~cm}$ depth) decreasing with depth (Fig. 8, bottom left panel). While the 20 and $40 \mathrm{~mm}$ pre-drought profiles show a maximum infiltration depth of about 45 and $30 \mathrm{~cm}$, respectively, the $60 \mathrm{~mm}$ pre-drought profile is stained below $70 \mathrm{~cm}$, exhibiting medium VD values (Fig. 8, bottom left panel). High SPW values are found in the $20 \mathrm{~mm}$ pre-drought profile up to a depth of $15 \mathrm{~cm}$ and in the 40 and $60 \mathrm{~mm}$ profiles up to 10 and $30 \mathrm{~cm}$, respectively. The drought profiles of the coniferous plots show far lower VD values in the top layers compared to the pre-drought profiles (Figs. 8 and 9, bottom left panels). The $40 \mathrm{~mm}$ drought profile exhibits even an unstained layer at about $5 \mathrm{~cm}$ depth. High SPW values can be found in the 40 and $60 \mathrm{~mm}$ drought profile, not in the top layers, but between 20 and $25 \mathrm{~cm}$ depth ( $40 \mathrm{~mm}$ profile), and between 10 and $25 \mathrm{~cm}$ depth $(60 \mathrm{~mm}$ profile) (Fig. 8 , bottom left panel). This is reflected in the flow-type classification. Whereas matrix flow dominates the top layers in pre-drought profiles (at least the top $10 \mathrm{~cm}$ ), matrix flow occurs below $10 \mathrm{~cm}$ depth in the 40 and $60 \mathrm{~mm}$ drought profiles (Fig. 8, bottom left panel).

\section{Schorfheide-Chorin deciduous plot}

The Schorfheide-Chorin deciduous pre-drought and drought patterns do not exhibit much differences in shape and in VD values in the 20 and $40 \mathrm{~mm}$ profiles (Fig. 8, bottom right panel). The largest differences in VDs can be found in the top $10 \mathrm{~cm}$ of the $20 \mathrm{~mm}$ profiles and in the $60 \mathrm{~mm}$ profile (Fig. 9 , bottom right panel). In addition, the $20 \mathrm{~mm}$ drought profile exhibits an unstained layer around $40 \mathrm{~cm}$ depth (Fig. 8, bottom right panel). The difference between pre-drought and drought is more evident in the SPW values: high SPW values are found in the 40 and $60 \mathrm{~mm}$ pre-drought profiles in the top and bottom half of the profile; high SPW values are found in the drought profile in the bottom half, plus a small layer of $2 \mathrm{~cm}$ of high SPWs around $10 \mathrm{~cm}$ depth in the $40 \mathrm{~mm}$ profile (Fig. 8, bottom right panel). In the Schorfheide-Chorin deciduous pre-drought profiles, flow types of the 40 and $60 \mathrm{~mm}$ are dominated by matrix flow (Fig. 8, bottom right panel). However, all profiles in the pre-drought plots have a proportion of macropore flow. In the drought profiles, matrix flow only occurs in the bottom half of the 40 and $60 \mathrm{~mm}$ profiles.

To summarize, compared with pre-drought infiltration pattern, the drought pattern of all plots reveal differences in infiltration processes. For example, over $90 \%$ of the depths ranges show significant differences in VDs between the drought and pre-drought site. Clayey and loamy soils be- have similarly, developing unwetted soil layers. High SPW values in 20 to $30 \mathrm{~cm}$ depth of the drought pattern indicate local saturation. In sandy soils, the change from high SPW values of the pre-drought pattern to medium and low in the drought pattern exhibit a change from front-like to a more scattered infiltration. In general, the effects were more pronounced at the coniferous plots. These findings correspond well with the results of the WDPT tests: in the clayey and loamy soils (except Hainich-Dün deciduous plot), the unstained topsoil layers coincide with the high WDPTs (Fig. 5). Hainich-Dün coniferous plots stay unwetted up to a depth of about 15 to $20 \mathrm{~cm}$ and Schwäbische Alb plots to a depth of about $10 \mathrm{~cm}$, which corresponds to the depths where the highest WDPT values were observed (Hainich-Dün: WDPT class 4; Schwäbische Alb: WDPT classes 4 and 3). In the sandy soils of the Schorfheide-Chorin profiles, low SPW values correspond to high WDPTs (class 2 and 3). Below the water repellent zone, SPW values increase again (Fig. 5, bottom panel).

\section{Discussion}

\subsection{Infiltration patterns and influence of main tree species}

The comparison of pre-drought infiltration patterns of the drought plots with patterns of the control plots (without drought treatment) showed broad agreements. All control plot profiles are comparable to the pre-drought plot profiles, including differences that can be addressed to small-scale heterogeneities of soil properties. When interpreting the patterns, the differences in VDs in the top layers of all plots need to be taken into account. When doing this, at all sites, the dye experiments before and during drought conditions can be directly compared.

In this study, it was hypothesized that the induced drought alters infiltration patterns due to changes in soil hydraulic properties (e.g., soil water repellency and forming of shrinkage cracks) and the main tree species has an effect on the magnitude of the response. The results of the infiltration experiment show clear evidence for changes in infiltration pattern as well as the importance of tree species on infiltration pattern: Schwäbische Alb plots have clayey soils with a high stone content, and show, in pre-drought and control plots, a slow and even infiltration. The drought-treated plots developed large areas with small volume densities and SPWs in the topsoil, while for deeper layers, broad stains (large SPWs) were observed, which cover the profiles for the most part (high VDs). This is typical for preferential flow that follows the shrinkage cracks of clayey soils or biopores of roots or soil fauna (Dekker and Ritsema, 2000; Hendrickx and Flury, 2001; Hardie et al., 2011). Water infiltrates quickly to deeper layers, bypassing a large proportion of the soil matrix. In deeper soil layers where the cracks or biopores end, 
local saturation occurs, and lateral redistribution into the soil matrix due to the now lower infiltration capacity and velocity can be observed. This also explains the similar pattern in the loamy Hainich-Dün soils.

A trend to more preferential flow was also observed in the Hainich-Dün plots, where the dense and loamy soils are also prone to shrinkage. Furthermore, in the Hainich-Dün drought profiles unstained (i.e., unwetted) areas in the topsoil layers were observed. This is more pronounced in the coniferous plot, where unstained areas were already visible in the pre-drought experiment. Preferential flow originates not only from cracks and biopores, but also from textual boundaries and instable wetting fronts (Doerr and Ritsema, 2006; Hendrickx and Flury, 2001). Unstable wetting fronts can occur due to air entrapment or hydrophobicity, which effectively hinders infiltration and redirects the water to structural and textural preferential flow paths (Doerr and Ritsema, 2006). The unwetted topsoil layers of the Hainich-Dün coniferous plots can be explained by the combination of severe water repellency and shrinkage cracks acting as effective bypasses.

In contrast to the other sites, Schorfheide-Chorin soils are sandy and highly permeable with low stone content. In both Schorfheide-Chorin plots, the infiltration patterns changed from a regular front-like stable infiltration to unstable, more scattered and fingered infiltration patterns. Following the conceptualization of unstable flow in water repellent soils by Ritsema et al. (1993, 2000), water flows, after entering the soil, through preferential pathways through the water repellent layer and distributes laterally in the divergence layer underneath. In fact, such flow patterns were pronounced in the Schorfheide-Chorin deciduous drought plot: medium VDs and SPWs up to a depth of 50-60 cm and larger SPWs in the layer beneath. This fits with the results of the WDPT tests, which show a slight to strong water repellency in the top 50$60 \mathrm{~cm}$ of the profile.

In general, drought induced major changes on the infiltration behavior of the examined soils. Clayey and loamy soils developed preferential flow. In these soils, the bypassing of the top $10-20 \mathrm{~cm}$ is fostered by water repellency, leading to unwetted topsoil layers. Sandy soils developed fingered infiltration patterns, due to the formation of a water repellent layer. In all three sites, the effects of the drought treatment were more pronounced in soils with coniferous main tree species than with deciduous main tree species.

\subsection{Water repellency}

In this study, it was hypothesized that the artificially induced drought will increase soil water repellency depending on the main tree species and soil properties. The highest water repellency was found in the coniferous plots of Schwäbische Alb and Hainich-Dün. Soils under coniferous trees often feature acidic soil conditions, which promote water repellency (Orfánus et al., 2014). In a study by Orfánus et al. (2014) liming practices and associated rise of $\mathrm{pH}$ values signifi- cantly reduced water repellency of former pine forest soils. Jost et al. (2004) explained the difference in recharge under a beech and a spruce forest stand, with higher hydrophobicity, and therefore the hindering of infiltration, combined with higher surface runoff of the spruce stand. This is in contrast to the findings of Buczko et al. (2006), who found the highest proportion of water repellent soils in pure beech stands compared to pure pine and mixed stands on sandy soils. However, in our study the sandy Schorfheide-Chorin plots showed higher mean WDPTs in the deciduous (beech) plot, than on the coniferous (pine) plot.

The soil texture can also influence the water repellency: a study of Gonzalez-Penaloza et al. (2013) suggests that water repellency is related to soil particle size. They induced water repellency by using different concentrations of stearic acid on samples of fine, medium and coarse sand. Water repellency was extreme in coarse-textured samples. The authors explained that by the lower specific surface compared to fine-textured samples and therefore smaller area that has to be covered by water repellent agents. We could not observe this effect in our sandy soils. The coarser-textured coniferous plot was less water repellent than the finer-textured deciduous Schorfheide-Chorin plot. However, water repellency can originate from a broad range of factors. The degree of water repellency of a soil also depends on the amount and type of organic matter that is incorporated in it (DeBano, 1981; Bisdom et al., 1993; Buczko et al., 2006; Vogelmann et al., 2013a, b), as well as the age and type of forest and litter type (Neris et al., 2013).

Several studies detected a significant impact of spruce litter on infiltration processes, either by hydrophobicity (Schume et al., 2004) or interception (Neris et al., 2013). Schume et al. (2004) found that spruce litter can intercept up to $5 \mathrm{~mm}$ of precipitation and Neris et al. (2013) found infiltration rates of $20 \mathrm{~mm} \mathrm{~h}^{-1}$ compared to that of $50 \mathrm{~mm} / \mathrm{h}$ of deciduous stands, doubling the runoff of the sites. In this study, we did not record the interception of the litter layer, which may have altered the total amount of water infiltrating into the soil. However, a natural litter layer is always present and intercepts precipitation (e.g., Gerrits et al., 2010). By keeping the natural litter layer in our experimental setup, our test results include the two influencing factors of the systems natural response in the infiltration pattern: the redistribution of incoming precipitation by the litter layer, leading to more spatial heterogeneous water input in the soil, compared to a soil with removed or hydrophilic litter layer. The measured infiltration pattern is a result of both factors, producing a more natural representation than a separate observation of litter layer and soil response.

Furthermore, the plants of the forest understory can also influence hydrophobicity of the soil; plants are covered with a cuticle composed of hydrophobic liquids, embedded in a polyester matrix and wax crystalloids (Holloway, 1994; Barthlott and Neinhus, 1997). Water repellent plant coatings can be found in all plant life forms with a clear dominance 
among herbs (Neinhus and Barthlott, 1997; Dekker and Ritsema, 2000). It has even been discussed that hydrophobic exudates might be a strategy for plants, microorganisms and fungi, to suppress germination and growth of competing vegetation by reducing evaporation and nutrient leaching (Doerr et al., 2007).

Hydrophobicity is dependent on the moisture status of the soil, which is defined by Doerr and Thomas (2003) as critical moisture or transition zone. Vogelmann et al. (2013a) found a critical water threshold of 0.36 to $0.57 \mathrm{~cm}^{3} \mathrm{~cm}^{-3}$ beyond which hydrophobic soils become hydrophilic, varying as a function of soil organic matter content. In contrast to the findings of Doerr and Thomas (2003), we found very similar water contents in drought-treated and control soils, but very different hydrophobicity conditions. This indicates that the drought history or, more generally, the climatic condition of a soil in the past is more important than the actual antecedent soil moisture status regarding hydrophobicity and infiltration behavior.

In our rainfall exclusion experiment drought stress was not intense enough to induce mortality or strong changes in aboveground biomass of a particular species (Gimbel et al., 2015). Nevertheless, drought and water repellency may promote the die-off of fine roots, which thereupon contribute to the total organic matter in the soil. The amount of soil organic matter and its composition has a strong influence on the strength of water repellency (e.g., Vogelmann et al., 2013a; Bisdom et al., 1993; DeBano, 1981). Therefore, the die-off of fine roots may lead to a self-reinforcing circle of water repellency.

Soil organic matter can form micro- and macro-aggregates by acting as binding agent between soil components (e.g., Tisdall and Oades, 1982; Annabi et al., 2011) or by covering soil particles (e.g., Vogelmann et al., 2013a). Vogelmann et al. (2013b) concluded in their study, that water repellency leads to slower wetting of soil aggregates. Therefore, cohesive forces hold up longer, which increases the resistance to disaggregation and, thus, indirectly aiding to maintaining soil structure. Terrestrial fungi are also in the focus of research concerning soil water repellency and aggregation (e.g., Tisdall and Oades, 1982; Rillig and Mummey, 2006; Chau et al., 2012). Zheng et al. (2014) found in three of nine species of ectomycorrhizal fungi associated with $P i$ nus sylvestris seedlings increased soil water repellency and in six of nine species an increase of water-stable aggregation. In our study, only the coniferous plot in Schorfheide-Chorin has Pinus sylvestris as the main tree species. In fact, the plot showed slight (mean values) to strong (maximum values) water repellency in the top $20 \mathrm{~cm}$. Nevertheless, the WDPT values of the deciduous plot in this area indicated stronger water repellency (in mean and maximum values).

All of our experimental plots showed clear response to the drought treatment, irrespective of their soil type and vegetation cover. Especially the fast bypassing of the topsoil layer and the development of unstained and hence unwetted ar- eas may bear consequences in the upcoming climate change. Sorption and degradation of contaminants is strongest in the topsoil and decrease with soil depth (Hendrickx and Flury, 2001). Thus, bypassing of the topsoil soil matrix foster early arrival times and high concentrations of contaminants in the groundwater, which was shown by several tracer field studies (e.g., Hendrickx and Flury, 2001; Ritsema et al., 1997; Hardie et al., 2011). Once formed, dry zones persist further wetting and additional water infiltrates through already existing preferential pathways, further stabilizing established flow paths (Dekker and Ritsema, 2000; Hagedorn and Bundt, 2002). Under present climate conditions, soil water repellency is already a widespread phenomenon (Buczko et al., 2006). For the predicted climate conditions, where droughts will be more common, an even higher level of hydrophobicity is to be expected, according to the findings of our rainfall reduction experiments.

\section{Conclusions}

Two years of rainfall reduction equivalent to an annual drought with a 40-year return interval was sufficient to change the soil properties and hence the infiltration pathways of six forest soils independent of soil type and tree species. All drought-treated soils, except one, developed slight to severe water repellency. Main tree species had a particular effect on hydrophobicity, but this only accounts for minor differences in infiltration pattern. The drought history or, more generally, the climatic condition in the past had more of an effect on the observed hydrophobicity and infiltration behavior than the actual antecedent soil moisture conditions of the soils. The results of this study suggest that drought effects on infiltration processes need to be considered in hydrological models to obtain realistic predictions regarding water quality and quantity in runoff and groundwater recharge.

Acknowledgements. The authors thank Emil Blattmann, Delon Wagner and Lukas Neuhaus for their technical assistance. Field support by Stefan Seeger, Frank Lehmann, Christoph Ries and Ruth Magh is gratefully acknowledged. The work has been funded by the DFG Priority Program 1374 "Infrastructure-BiodiversityExploratories" (DFG-Refno. WE4598/3-1, GE1090/11-1 and BR1698/16-1). We thank the managers of the three Biodiversity Exploratories frameworks, Swen Renner, Sonja Gockel, Andreas Hemp, Martin Gorke and Simone Pfeiffer for their work in maintaining the plot and project infrastructure, and Markus Fischer, the late Elisabeth Kalko, Eduard Linsenmair, Dominik Hessenmöller, Jens Nieschulze, Daniel Prati, Ingo Schöning, François Buscot, Ernst-Detlef Schulze and Wolfgang W. Weisser for their role in setting up the Biodiversity Exploratories project. Field work permits were issued by the responsible state environmental offices of Baden-Württemberg, Thüringen, and Brandenburg

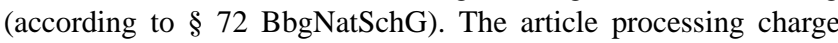
was funded by the German Research Foundation (DFG) and the 
Albert Ludwigs University Freiburg in the funding programme Open-Access Publishing.

Edited by: M. Hrachowitz

\section{References}

Albert, K. R., Ro-Poulsen, H., Mikkelsen, T. N., Michelsen, A., van der Linden, L., and Beier, C.: Effects of elevated $\mathrm{CO}_{2}$, warming and drought episodes on plant carbon uptake in a temperate heath ecosystem are controlled by soil water status, Plant Cell Environ., 34, 1207-1222, doi:10.1111/j.1365-3040.2011.02320.x, 2011.

Annabi, M., Le Bissonnais, Y., Le Villio-Poitrenaud, M., and Houot, S.: Improvement of soil aggregate stability by repeated applications of organic amendments to a cultivated silty loam soil, Agr. Ecosyst. Environ., 144, 382-389, doi:10.1016/j.agee.2011.07.005, 2011.

Bachmair, S., Weiler, M., and Nützmann, G.: Controls of land use and soil structure on water movement: Lessons for pollutant transfer through the unsaturated zone, J. Hydrol., 369, 241-252, doi:10.1016/j.jhydrol.2009.02.031, 2009.

Barthlott, W. and Neinhuis, C.: Purity of the sacred lotus, or escape from contamination in biological surfaces, Planta, 202, 1-8, doi:10.1007/s004250050096, 1997.

Bisdom, E., Dekker, L. W., and Schoute, J.: Water repellency of sieve fractions from sandy soils and relationships with organic material and soil structure, Geoderma, 56, 105-118, doi:10.1016/0016-7061(93)90103-R, 1993.

Buczko, U., Bens, O., and Hüttl, R. F.: Water infiltration and hydrophobicity in forest soils of a pine-beech transformation chronosequence, J. Hydrol., 331, 383-395, doi:10.1016/j.jhydrol.2006.05.023, 2006.

Bütof, A., von Riedmatten, Lars R., Dormann, C. F., SchererLorenzen, M., Welk, E., and Bruelheide, H.: The responses of grassland plants to experimentally simulated climate change depend on land use and region, Global Change Biol., 18, 127-137, doi:10.1111/j.1365-2486.2011.02539.x, 2012.

Chau, H. W., Goh, Y. K., Vujanovic, V., and Si, B. C.: Wetting properties of fungi mycelium alter soil infiltration and soil water repellency in a $\gamma$-sterilized wettable and repellent soil, Fungal Biology, 116, 1212-1218, doi:10.1016/j.funbio.2012.10.004, 2012.

da Costa, A. C. L., Galbraith, D., Almeida, S., Portela, B., Tanaka, T., da Costa, M., de Athaydes Silva Jr., J., Braga, A. P., de Gonçalves, P. H. L., de Oliveira, A. A. R., Fisher, R., Phillips, O. L., Metcalfe, D. B., Levy, P., and Meir, P.: Effect of 7 yr of experimental drought on vegetation dynamics and biomass storage of an eastern Amazonian rainforest, New Phytol., 187, 579-591, doi:10.1111/j.1469-8137.2010.03309.x, 2010.

DeBano, L. F.: Water repellent soils: a state-of-the-art, USDA For. Serv. Gen. Tech. Rep. PSW-46, USDA, Pacific Southwest Forest and Range Experiment Station, Berkeley, California, 21 pp., 1981.

DeBano, L. F.: Water repellency in soils: a historical overview, J. Hydrol., 231-232, 4-32, doi:10.1016/S0022-1694(00)00180-3, 2000.

Dekker, L. W. and Ritsema, C. J.: Wetting patterns and moisture variability in water repellent Dutch soils, J. Hydrol., 231-232, 148-164, doi:10.1016/S0022-1694(00)00191-8, 2000.
Dermody, O., Weltzin, J. F., Engel, E. C., Allen, P., and Norby, R. J.: How do elevated $\left[\mathrm{CO}_{2}\right]$, warming, and reduced precipitation interact to affect soil moisture and LAI in an old field ecosystem?, Plant Soil, 301, 255-266, doi:10.1007/s11104-007-9443$\mathrm{x}, 2007$.

Doerr, S. H. and Ritsema, C. J.: Water Movement in Hydrophobic Soils, in: Encyclopedia of Hydrological Sciences, John Wiley \& Sons, Ltd, doi:10.1002/0470848944, 2006.

Doerr, S. H. and Thomas, A. D.: Soil moisture: a controlling factor in water repellency?, in: Soil Water Repellency: Occurrence, Consequences and Amelioration, edited by: Ritsema, C. J. and Dekker, L. W., Elsevier Science, Amsterdam, 137-149, 2003.

Doerr, S. H., Ritsema, C. J., Dekker, L. W., Scott, D. F., and Carter, D.: Water repellence of soils: new insights and emerging research needs, Hydrol. Process., 21, 2223-2228, doi:10.1002/hyp.6762, 2007.

English, N. B., Weltzin, J. F., Fravolini, A., Thomas, L., and Williams, D. G.: The influence of soil texture and vegetation on soil moisture under rainout shelters in a semi-desert grassland, J. Arid Environ., 63, 324-343, doi:10.1016/j.jaridenv.2005.03.013, 2005.

FAO: Guidelines for Soil Description, 4th Edn., Food and Agriculture Organization of the United Nations, Rome, 2006.

Fischer, M., Bossdorf, O., Gockel, S., Hänsel, F., Hemp, A., Hessenmöller, D., Korte, G., Nieschulze, J., Pfeiffer, S., Prati, D. R. S., Schöning, I., Schumacher, U., Wells, K., Buscot, F., Kalko, E. K. V., Linsenmair, K. E., Schulze, E.-D., and Weisser, W. W.: Implementing large-scale and long-term functional biodiversity research: The Biodiversity Exploratories, Basic Appl. Ecol., 11, 473-485, doi:10.1016/j.baae.2010.07.009, 2010.

Gerrits, A. M. J., Pfister, L., and Savenije, H. H. G.: Spatial and temporal variability of canopy and forest floor interception in a beech forest, Hydrol. Process., 24, 3011-3025, doi:10.1002/hyp.7712, 2010.

Gimbel, K. F., Felsmann, K., Baudis, M., Puhlmann, H., Gessler, A., Bruelheide, H., Kayler, Z., Ellerbrock, R. H., Ulrich, A., Welk, E., and Weiler, M.: Drought in forest understory ecosystems a novel rainfall reduction experiment, Biogeosciences, 12, 961975, doi:10.5194/bg-12-961-2015, 2015.

Glaser, B., Jentsch, A., Kreyling, J., and Beierkuhnlein, C.: Soil-moisture change caused by experimental extreme summer drought is similar to natural inter-annual variation in a loamy sand in Central Europe, Z. Pflanzenernähr. Bodenk., 176, 27-34, doi:10.1002/jpln.201200188, 2013.

González-Peñaloza, F. A., Zavala, L. M., Jordán, A., Bellinfante, N., Bárcenas-Moreno, G., Mataix-Solera, J., Granged, A. J., GranjaMartins, F. M., and Neto-Paixão, H. M.: Water repellency as conditioned by particle size and drying in hydrophobized sand, Geoderma, 209-210, 31-40, doi:10.1016/j.geoderma.2013.05.022, 2013.

Hagedorn, F. and Bundt, M.: The age of preferential flow paths, Geoderma, 108, 119-132, doi:10.1016/S0016-7061(02)00129-5, 2002.

Hardie, M. A., Cotching, W. E., Doyle, R. B., Holz, G., Lisson, S., and Mattern, K.: Effect of antecedent soil moisture on preferential flow in a texture-contrast soil, J. Hydrol., 398, 191-201, doi:10.1016/j.jhydrol.2010.12.008, 2011.

Hendrickx, J. M. H. and Flury, M.: Uniform and preferential flow mechanisms in the vadose zone, in: Conceptual models 
of flow and transport in the fractured vadose zone, Panel on Conceptual Models of Flow and Transport in the Fractured Vadose Zone, US National Committee for Rock Mechanics, Board on Earth Sciences and Resources, National Research Council, National Academy Press, Washington, D.C., 149-187, doi:10.17226/10102, 2001.

Holloway, P. J.: Plant cuticles: physiochemical characteristics and biosynthesis, in: Air Pollution and the Leaf Cuticle, edited by: Percy, K. E., Springer, Berlin, 1-13, 1994.

IPCC: Managing the Risks of Extreme Events and Disasters to Advance Climate Change Adaptation, in: A Special Report of Working Groups I and II of the Intergovernmental Panel on Climate Change, edited by: Field, C. B., Barros, V., Stocker, T. F., Qin, D., Dokken, D. J., Ebi, K. L., Mastrandrea, M. D., Mach, K. J., Plattner, G.-K., Allen, S. K., Tignor, M., and Midgley, P. M., Cambridge University Press, Cambridge, UK, and New York, NY, USA, 582 pp., 2012.

Jost, G., Schume, H., and Hager, H.: Factors controlling soil waterrecharge in a mixed European beech (Fagus sylvatica L.) Norway spruce [Picea abies (L.) Karst.] stand, Eur. J. Forest Res., 123, 93-104, doi:10.1007/s10342-004-0033-7, 2004.

Keesstra, S. D., Geissen, V., Mosse, K., Piiranen, S., Scudiero, E., Leistra, M., and van Schaik, L.: Soil as a filter for groundwater quality, Curr. Opin. Environ. Sustain., 4, 507-516, doi:10.1016/j.cosust.2012.10.007, 2012.

Kopittke, G. R., Tietema, A., Loon, E. E., and Asscheman, D.: Fourteen Annually Repeated Droughts Suppressed Autotrophic Soil Respiration and Resulted in an Ecosystem Change, Ecosystems, 17, 242-257, doi:10.1007/s10021-013-9720-x, 2014.

Meijer, S. S., Holmgren, M., and Van der Putten, W. H.: Effects of plant-soil feedback on tree seedling growth under arid conditions, J. Plant Ecol., 4, 193-200, doi:10.1093/jpe/rtr011, 2011.

Neinhuis, C. and Barthlott, W.: Characterization and Distribution of Water-repellent, Self-cleaning Plant Surfaces, Ann. Bot., 79, 667-677, doi:10.1006/anbo.1997.0400, 1997.

Neris, J., Tejedor, M., Rodríguez, M., Fuentes, J., and Jiménez, C.: Effect of forest floor characteristics on water repellency, infiltration, runoff and soil loss in Andisols of Tenerife (Canary Islands, Spain), Catena, 108, 50-57, doi:10.1016/j.catena.2012.04.011, 2013.

Orfánus, T., Dlapa, P., Fodor, N., Rajkai, K., Sándor, R., and Nováková, K.: How severe and subcritical water repellency determines the seasonal infiltration in natural and cultivated sandy soils, Soil Till. Res., 135, 49-59, doi:10.1016/j.still.2013.09.005, 2014.

Ozolinčius, R., Stakėnas, V., Varnagirytė-Kabašinskienè, I., and Buožytė, R.: Artificial Drought in Scots Pine Stands: Effects on Soil, Ground Vegetation and Tree Condition, Annales Botanici Fennici, 46, 299-307, doi:10.5735/085.046.0406, 2009.

Phillips, O. L., Aragao, L. E. O. C., Lewis, S. L., Fisher, J. B., Lloyd, J., Lopez-Gonzalez, G., Malhi, Y., Monteagudo, A., Peacock, J., Quesada, C. A., van der Heijden, G., Almeida, S., Amaral, I., Arroyo, L., Aymard, G., Baker, T. R., Banki, O., Blanc, L., Bonal, D., Brando, P., Chave, J., de Oliveira, A. C. A., Cardozo, N. D., Czimczik, C. I., Feldpausch, T. R., Freitas, M. A., Gloor, E., Higuchi, N., Jimenez, E., Lloyd, G., Meir, P., Mendoza, C., Morel, A., Neill, D. A., Nepstad, D., Patino, S., Penuela, M. C., Prieto, A., Ramirez, F., Schwarz, M., Silva, J., Silveira, M., Thomas, A. S., Steege, H. T., Stropp, J., Vasquez, R., Zelazowski,
P., Davila, E. A., Andelman, S., Andrade, A., Chao, K.-J., Erwin, T., Di Fiore, A., C., E. H., Keeling, H., Killeen, T. J., Laurance, W. F., Cruz, A. P., Pitman, N. C. A., Vargas, P. N., RamirezAngulo, H., Rudas, A., Salamao, R., Silva, N., Terborgh, J., and Torres-Lezama, A.: Drought Sensitivity of the Amazon Rainforest, Science, 323, 1344-1347, doi:10.1126/science.1164033, 2009.

Prudhomme, C., Giuntoli, I., Robinson, E. L., Clark, D. B., Arnell, N. W., Dankers, R., Fekete, B. M., Franssen, W., Gerten, D., Gosling, S. N., Hagemann, S., Hannah, D. M., Kim, H., Masaki, Y., Satoh, Y., Stacke, T., Wada, Y., and Wisser, D.: Hydrological droughts in the 21st century, hotspots and uncertainties from a global multimodel ensemble experiment, P. Natl. Acad. Sci., 111, 3262-3267, doi:10.1073/pnas.1222473110, 2014.

Rillig, M. C. and Mummey, D. L.: Mycorrhizas and soil structure. New Phytol., 171, 41-53, 2006.

Ritsema, C. J. and Dekker, L.: Preferential flow in water repellent sandy soils: principles and modeling implications, J. Hydrol., 231-232, 308-319, doi:10.1016/S0022-1694(00)00203-1, 2000.

Ritsema, C. J., Dekker, L. W., Hendrickx, J. M. H., and Hamminga, W.: Preferential flow mechanism in a water repellent sandy soil, Water Resour. Res., 29, 2183-2193, doi:10.1029/93WR00394, 1993.

Ritsema, C. J., Dekker, L. W., van den Elsen, E. G. M., Oostindiel, K., Steenhuis, T. S., and Nieber, J. L.: Recurring fingered flow pathways in a water repellent sandy field soil, Hydrol. Earth Syst. Sci., 1, 777-786, doi:10.5194/hess-1-777-1997, 1997.

Schume, H., Jost, G., and Hager, H.: Soil water depletion and recharge patterns in mixed and pure forest stands of European beech and Norway spruce, J. Hydrol., 289, 258-274, doi:10.1016/j.jhydrol.2003.11.036, 2004.

Selsted, M. B., Linden, L., Ibrom, A., Michelsen, A., Larsen, K. S., Pedersen, J. K., Mikkelsen, T. N., Pilegaard, K., Beier, C., and Ambus, P.: Soil respiration is stimulated by elevated $\mathrm{CO}_{2}$ and reduced by summer drought: three years of measurements in a multifactor ecosystem manipulation experiment in a temperate heathland (CLIMAITE), Global Change Biol., 18, 1216-1230, doi:10.1111/j.1365-2486.2011.02634.x, 2012.

Seneviratne, S. I., Luethi, D., Litschi, M., and Schaer, C.: Landatmosphere coupling and climate change in Europe, Nature, 443, 205-209, doi:10.1038/nature05095, 2006.

Suttle, B. K. and Thomsen, M. A.: Climate change and grassland restoration in California: Lessons from six years of rainfall manipulation in a North Coast grassland, Madroño, 54, 225-233, doi:10.3120/0024-9637(2007)54[225:CCAGRI]2.0.CO;2, 2007.

Tisdall, J. M. and Oades, J. M.: Organic matter and water-stable aggregates in soils, J. Soil Sci., 33, 141-163, 1982.

Vogelmann, E. S., Reichert, J. M., Prevedello, J., Consensa, C., Oliveira, A., Awe, G. O., and Mataix-Solera, J.: Threshold water content beyond which hydrophobic soils become hydrophilic: The role of soil texture and organic matter content, Geoderma, 209-210, 177-187, doi:10.1016/j.geoderma.2013.06.019, 2013a.

Vogelmann, E. S., Reichert, J. M., Prevedello, J., Awe, G. O., and Mataix-Solera, J.: Can occurrence of soil hydrophobicity promote the increase of aggregates stability?, Catena, 110, 24-31, doi:10.1016/j.catena.2013.06.009, 2013b. 
Weibel, E. R.: Stereological Methods, in: Vol. 1: Practical Methods for Biological Morphometry, Academic Press, New York, 396 pp., 1979.

Weiler, M.: Mechanics Controlling Macropore flow during Infiltration - dye Tracer Experiments and Simulations, ETH, Zürich, Swizerland, 151 pp., 2001.

Weiler, M. and Flühler, H.: Inferring flow types from dye patterns in macroporous soils, Geoderma, 120, 137-153, doi:10.1016/j.geoderma.2003.08.014, 2004.

Weiler, M. and Naef, F.: An experimental tracer study of the role of macropores in infiltration in grassland soils, Hydrol. Process., 17, 477-493, 2003.
World reference base for soil resources: A framework for international classification, correlation and communication, 2006 Edn., World soil resources reports 103, Food and Agriculture Organization of the United Nations, Rome, 2006.

Wu, C. and Chen, J. M.: Diverse responses of vegetation production to interannual summer drought in North America, Int. J. Appl. Earth Obs. Geoinf., 21, 1-6, doi:10.1016/j.jag.2012.08.001, 2013.

Zheng, W., Morris, E. K., and Rillig, M. C.: Ectomycorrhizal fungi in association with Pinus sylvestris seedlings promote soil aggregation and soil water repellency, Soil Biol. Biochem., 78, 326331, doi:10.1016/j.soilbio.2014.07.015, 2014. 